\title{
Association of Psychological Factors to Alcohol Consumption Behavior among U.S. College Students
}

By

*Oladunni Oluwoye; Salam Khan, Ph.D.; Jacob Oluwoye, Ph.D; Russell J. Fricano, Ph.D.; Earl M. Gooding, Ph.D.; Joan Fobbs-Wilson, Ph.D.; Jitendra Kapoor, Ph.D.

\begin{abstract}
This study explores college students' alcohol consumption behavior and evaluates the effect of different psychological factors on consumption patterns. Randomly selected students from two different universities completed surveys with perceived scales for stress, self esteem and anxiety and an alcohol consumption questionnaire. Non-parametric analyses suggests that low self esteem, higher stress and anxiety level and younger age increase the likelihood of drinking alcohol. These findings were consistent between both universities. These findings have important implications for the selection of appropriate interventional strategies and health education among college populations.
\end{abstract}

Key Words: Self Esteem, Stress, Psychological Factors, Alcohol Consumption, Behavior, College Students.

\section{Introduction}

Universities are known for a social as well as an academic environment. Many students identify with movies which show college students using alcohol, tobacco, marijuana and other substances and argue that they exemplify the social scene of university life and university students. To what point is a university known for its social rather than its academic status? All universities have a social scene, which is comprised of parties, smoking, alcohol consumption, and other substance usage. Is this social aspect automatically associated with university students? At this time the answer to this question is, "Yes". However, whether this social aspect is solely attributed to the university environment or to other factors including varied psychological factors, a student's family history or peer pressure, remains open to further examination.

Substance abuse among university students within the United States has been recognized as a major public health problem (Dhanookdhary et al., 2010; Ham \& Hope, 
2003) and associated with adverse consequences of suicide, negative educational outcomes, criminal behaviors, psychological difficulties, and severe drug abuse (Windle, 2003). An understanding of the psychological factors and other issues that place university students at greater risk for substance usage and abuse (SUA) is critical for the development of effective intervention and preventative measures. Smoking behavior is the starting point of all these kinds of high risk behavior.

The use of tobacco among university students has been of concern due to the underlying issues that may arise from adverse use. Recent studies have shown that there are high rates of smoking in university students in the United States of America. Smoking has decreased in all age groups except the 18-24 age groups which are the primary age range for university students (Rigotti, Morgan, \& Wechsler, 2005). University students are more prone to trying or experimenting with various tobacco substances and are at high risk of developing lifelong addictions (Rigotti, Lee, \& Wechler, 2000).

Alcohol consumption and addiction among university students has also been identified as a critical public health issue over the recent years (Patterson, Lerman, Kaufmann, Neuner, \& Audrain-McGovern, 2004). Consequently there is a critical need to understand why university students are at higher risk for abuse of all substances at levels of education of twelve or more years.

Deas and Thomas (2002) define psychological factors as "patterns of thought and behavior that exist along a continuum in the general population - including for example, personality traits, self-esteem, and coping skills" (p.1). Psychological factors are generally related to behaviors and thought patterns that may influence drug and alcohol use and smoking behavior. Deas and Thomas (2002) further noted that stressful and/or traumatic events also suggest an increased risk for developing smoking behavior. These findings were made evident by Kilpatrick, Acierno, Saunders, Resnick, Best \& Schnurr (2000); their research found that adolescents who witnessed and experienced stressful, violent, or traumatic situations were more inclined to experiment with various substances such as smoking, alcohol and other drugs.

For university students the value of friendships and social aspects can compensate for lack of family structure within the university environment. There is a major shift from parental influence to peer influence once students enter into college, to which friendships can allow for and determine levels of self-esteem and self- worth (Hartup, 1999).

Peer pressure, in particular, has been linked to substance usage in adolescents and has also been linked to high-risk behavior (Deas \& Thomas, 2002; Santor, Messervey, \& Kusumakar, 2000). The quality of the relationship between university students and their peers, as well as the type of peers they associate with, play important roles in aiding or impeding their current and future functioning. Although research has suggested that peer pressure is directly correlated to the consumption and use of illicit substances and 
misconduct behaviors, peer pressure also has an effect on other areas also, such as family relationships and level of involvement in school (Clasen \& Brown, 1986). Further, certain aspects of peer relations are unique to the culture and environment in which they exist.

\section{Purpose of the Study}

The purpose of this study is to evaluate and understand the psychological factors behind alcohol consumption behavior of undergraduate students. The rationale for studying this population is based on the fact that full-time undergraduate students are likely to have a high usage rate of substances, which includes alcohol consumption; this may ultimately lead to adverse consequences. This study explored college students' alcohol consumption behavior and identifies the effect of different psychological factors. The use of psychological theories can be linked to structured intervention and prevention programs which could be implemented in universities throughout the United States.

\section{Research Methodology}

The participants of this study included a sample of approximately 250-300 undergraduate students at Alabama A\&M University (AAMU) and the University of Alabama at Birmingham (UAB). AAMU is a Historically Black College and University (HBCU) in Normal, Alabama within the Huntsville Metropolitan Statistical Area. AAMU has an enrollment of approximately 5,800 students. UAB, which is located within the Birmingham, Alabama MSA, is a Predominately White Institution (PWI). UAB has an enrollment of approximately 17,500 students. Both universities have culturally diverse populations.

The following variables were used in this study: information about alcohol consumption behavior, self esteem levels, anxiety levels; stress levels and age.

1. Demographics Form: Participants were required to provide information about their age, gender, ethnicity, residence, family income and parents' education on the questionnaire but not their names;

2. Survey: The survey used in this study was developed by the World Health Organization to collect information on the use of alcohol. Research by Atowi, Mungla, Ndunga'u, Kinoti \& Ogot (2011) and Peltzer, Malaka, \& Phaswana (2002) have both reported using the Model Core Questionnaire to obtain information with respect to tobacco. The participants was asked, (ii) what they have used over the past 30 days, (iii) average amount consumed per episode, (iv) reasons for use, (v) side effects experienced when alcohol consumption, (vi) parents' knowledge of use, (vii) change in consumption patterns upon entering university, (viii) other family members consumption;

3. The Rosenberg Self-Esteem Scale (SES): The SES developed by Roseburg (1965) was used to measure the participants' level of self-esteem. The scale is a ten item Likert scale with items answered on a four-point scale (strongly agree to strongly disagree). Scores range from 10-40 with higher scales corresponding to higher selfesteem. The internal consistency is a Cronbach Alpha of 0.77 ; 
4. The Perceived Stress Scale (PSS): The PSS is a 10-point scale based upon the participants' feelings and thoughts over the previous month (Cohen, Kamarck, \& Mermelstein, 1983). The scale employs responses on a 4-point Likert Scale (never to very often). The coefficient alpha reliability for the four-item PSS was 0.72. The test-retest over a two month time frame was 0.55 ; and

5. Taylor Manifest Anxiety Scale: The Taylor Manifest Anxiety Scale (Taylor, 1953) is a 50 item true or false scale. It was subsequently used as a general indicator of anxiety. True or false responses are used, and the replies indicating anxiety are counted, giving a score from 0 to 50, with higher scores representing higher levels of anxiety. The coefficient alpha reliability was 0.70 from a sample of graduate students. Taylor (1953) reported the retest correlations of $0.89,0.82$, and 0.81 over three weeks, five months, and nine to seventeen months (Livneh \& Redding, 1986).

Participants were asked to complete the demographics form. Survey participants also completed the Youth Survey Questionnaire to assess the alcohol consumption behavior. The SES was being used to evaluate the respondent's own self-esteem. The PSS was being served as an additional scale to measure stress among students.

Each participant was provided with an informed consent form before participating in the study. This form was stored at the respective university's Institutional Review Board (IRB). Participants were required to show a valid university identification card to ensure that they were actually full-time, undergraduate students at both facilities. Once the study has been completed and turned into the proctor, each participant was thanked for willingly participating in the study and then debriefed regarding the purpose and objectives of the study.

The Statistical Analysis System (SAS) program was used to obtain descriptive and non parametric inferential analysis of the data. Spearman Rank Order Correlations were also used to determine the strength of the association between the variables. The initial hypothesis was that there is no association between alcohol consumption behavior and psychological factors.

\section{Data Analysis for Alabama A\&M University (AAMU) participants}

\subsection{Self Esteem}

The authors analyzed the data to measure the association between the alcohol consumptions and self esteem levels among AAMU students. The scatter plot indicated in Figure 1 shows that many respondents with high self esteem did not report alcohol consumption (designated as 2). By using Spearman Rank Order Correlation we can see that alcohol consumption and self esteem have a significant weak positive correlation and the Spearman Rank order correlation is 0.118141 . According to this test, higher self esteem is associated with not drinking alcohol (see Table 1). 


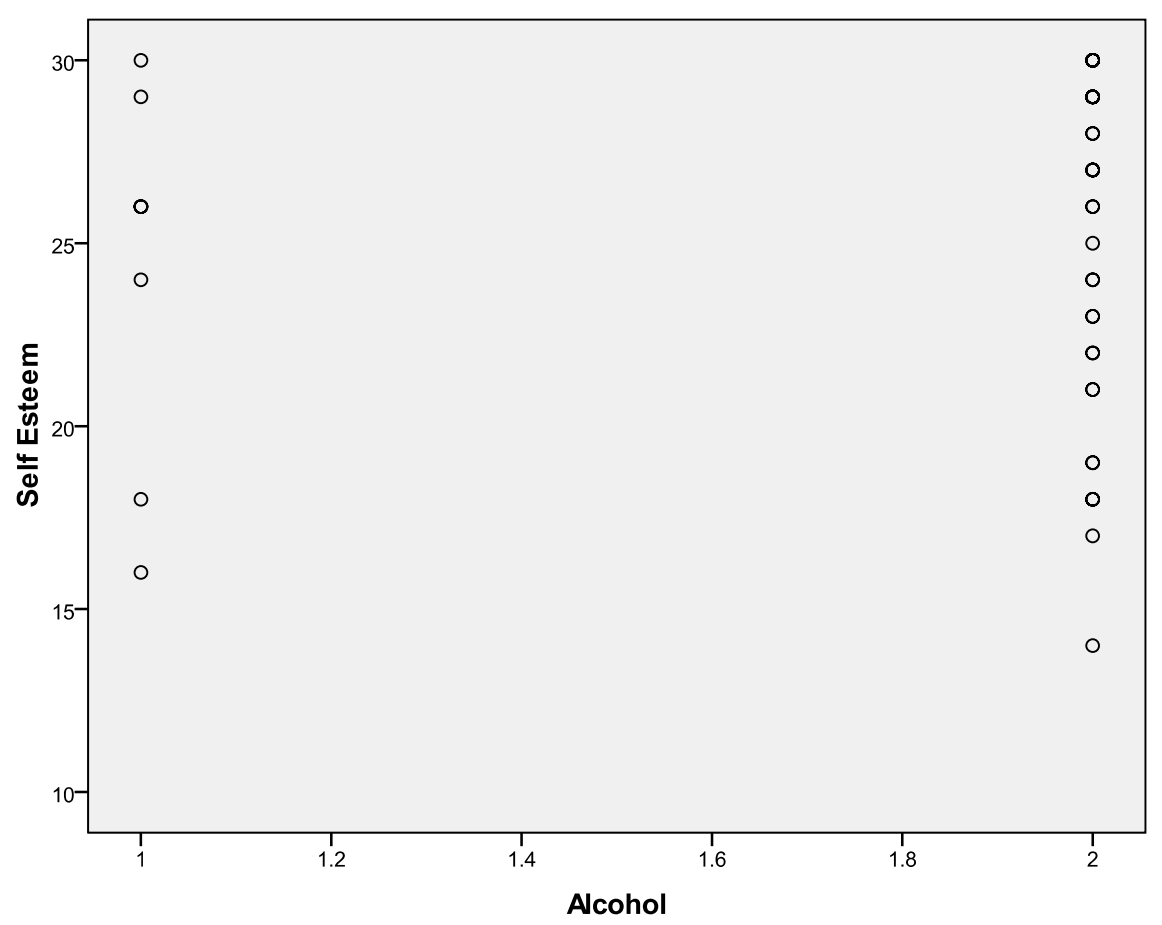

Figure 1. Scatter plot of alcohol consumption and self esteem among AAMU participants.

Table 1. Spearman Rank Order Correlation between Alcohol Consumption and Self Esteem among AAMU Participants

\begin{tabular}{ccc}
\hline Variable & Alcohol Consumption & Self Esteem \\
\hline Alcohol Consumption & 1.0 & 0.118141 \\
Self Esteem & 0.118141 & 1.0 \\
\hline
\end{tabular}

\subsection{Stress}

Correlations are significant at $\mathrm{p}<05000$.

The authors next analyzed the association between the alcohol consumption and stress levels. The scatter plot in Figure 2 shows that respondents with higher stress levels are more likely to drink alcohol (which is designated as 1) than the respondents with lower stress levels. Table 2 lists the Spearman Rank Order Correlation values. By using Spearman Rank Order Correlation we can see that alcohol consumption and stress have significant negative correlation with a correlation of -0.213009 . This indicates that higher stress levels are associated with alcohol consumption. 


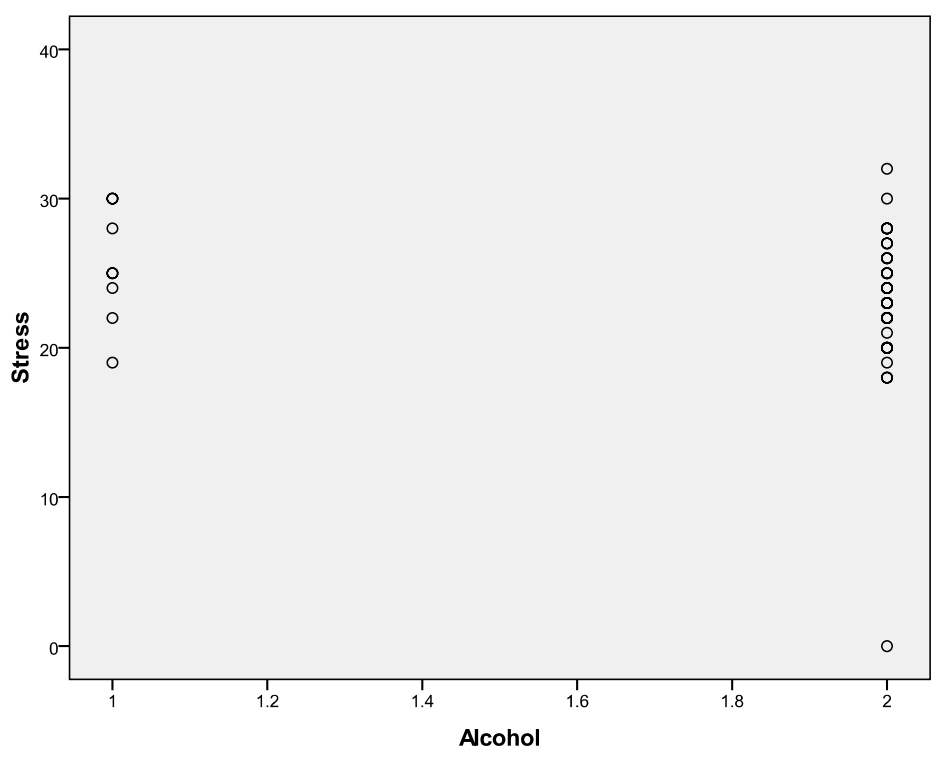

Figure 2. Scatter plot of alcohol consumption and stress among AAMU participants.

Table 2. Spearman Rank Order Correlation between Alcohol Consumption and Stress among AAMU Participants

\begin{tabular}{ccc}
\hline Variable & Alcohol Consumption & Stress \\
\hline Alcohol Consumption & 1.0 & -0.213009 \\
Stress & -0.213009 & 1.0 \\
\hline
\end{tabular}

Correlations are significant at $\mathrm{p}<05000$.

\subsection{Anxiety}

The authors also examined the association between the alcohol consumptions and anxiety levels. The scatter plot depicted in Figure 3 shows that respondents with higher anxiety levels are more likely to drink alcohol (depicted as 1) than respondents with lower stress levels. The outcome of the Spearman Rank Order Correlation analysis between alcohol consumption and anxiety is indicated in Table 3. We found a significant and weak negative correlation between these variables of -0.150556 . This shows that a higher anxiety level is associated with alcohol consumption. 


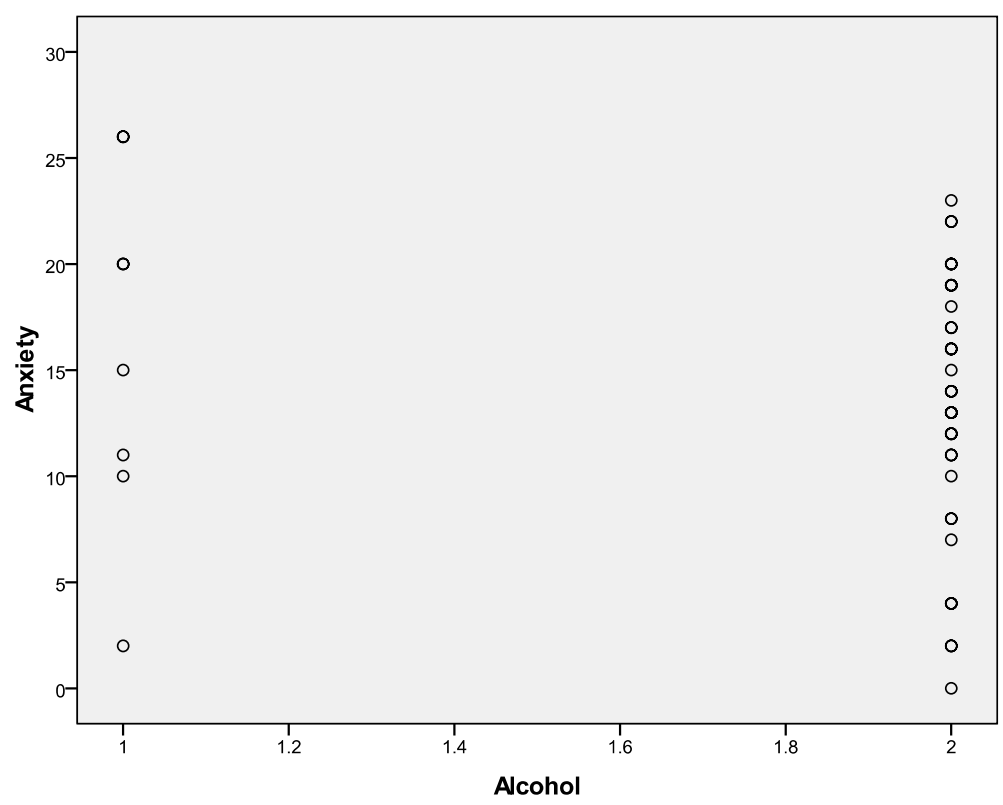

Figure 3. Scatter plot of alcohol consumption and anxiety among AAMU participants.

Table 3. Spearman Rank Order Correlation between Alcohol Consumption and Anxiety among AAMU Participants

\begin{tabular}{ccc}
\hline Variable & Alcohol Consumption & Anxiety \\
\hline & & \\
Alcohol Consumption & 1.0 & -0.150556 \\
Anxiety & -0.150556 & 1.0 \\
\hline
\end{tabular}

Correlations are significant at $\mathrm{p}<05000$.

\subsection{Age}

The authors also analyzed survey data to examine the association between alcohol consumption and age. The scatter plot indicated in Figure 4 shows that younger respondents are more likely to drink alcohol (which is assigned a value of 1) than older respondents. By using Spearman Rank Order Correlation we can see these variables demonstrate a weak positive correlation of 0.163997 . This indicates that younger students are more likely to be associated with higher levels of alcohol consumption than older students. 


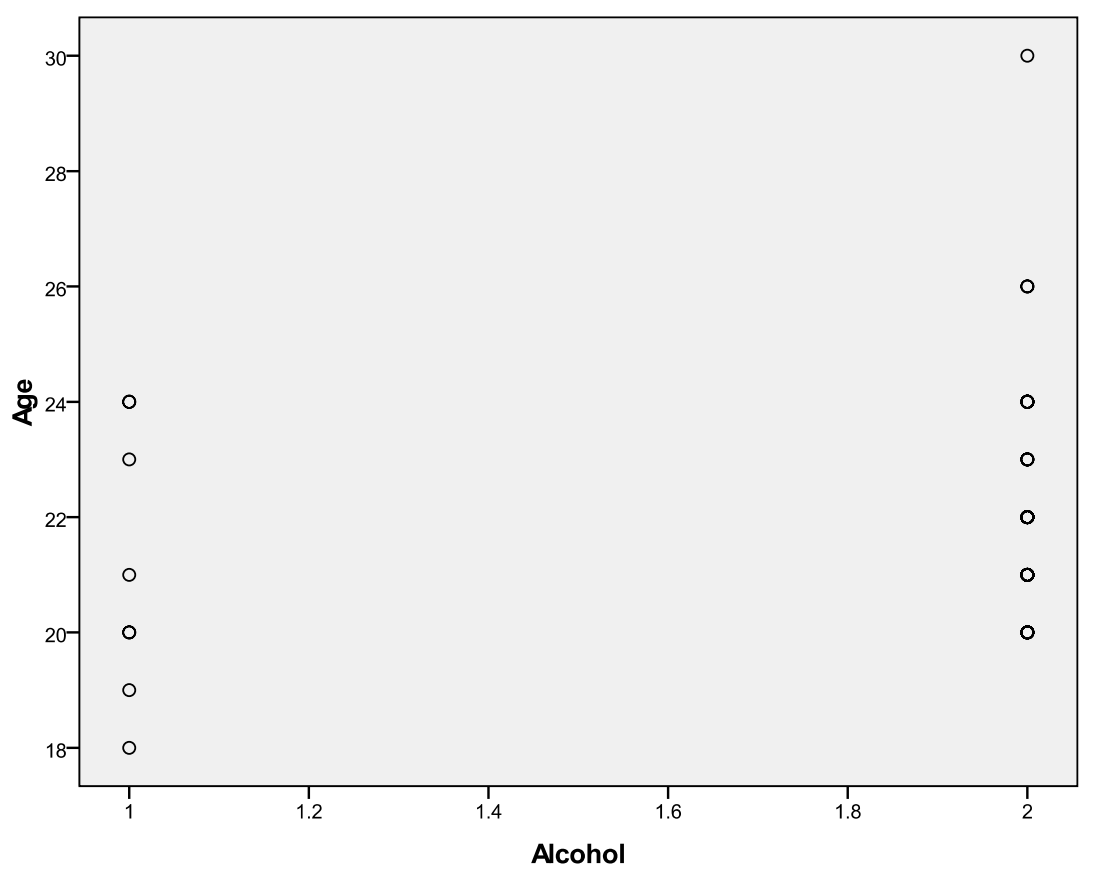

Figure 4. Scatter plot of alcohol consumption and age among AAMU participants.

Table 4. Spearman Rank Order Correlation between alcohol consumption and age among AAMU participants

\begin{tabular}{ccc}
\hline Variable & Alcohol Consumption & Age \\
\hline Alcohol Consumption & 1.0 & 0.163997 \\
Age & 0.163997 & 1.0 \\
\hline
\end{tabular}

Correlations are significant at $\mathrm{p}<05000$.

\section{AAMU Respondents: Summary Statistical Analysis}

Figures 5, 6 and 7 provide a summary statistical analysis of the distribution of respondent observations using descriptive statistics, a histogram and P-plot for self esteem, anxiety, stress and age. A sample of 50 AAMU students responded to survey. The average age of the AAMU respondent is 22 years, ranging from 18 to 30 years. The average self esteem level for AAMU respondents is 25.33. AAMU respondents also had mean stress levels of 23.3. The average anxiety level for AAMU respondents is 13.81. In this analysis each variable demonstrated distribution of responses consistent with the correlation analysis. 


\section{Summary: Self Esteem}
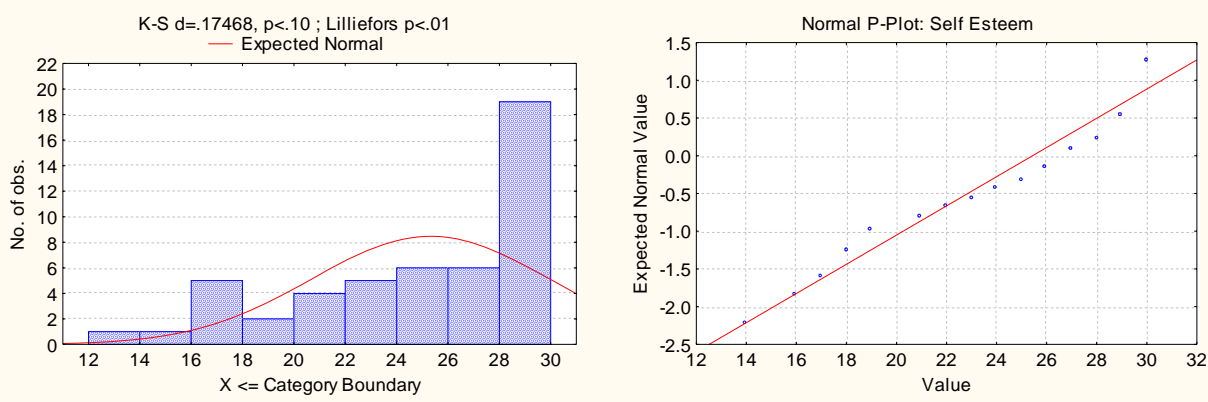

\section{Valid $\mathrm{N}=49$ \\ Mean $=25.326531$ \\ Median $=27.000000$ \\ Minimum $=14.000000$ \\ Maximum $=30.000000$ \\ Std.Dev. $=4.616040$}

Summary Statistics:Self Esteem

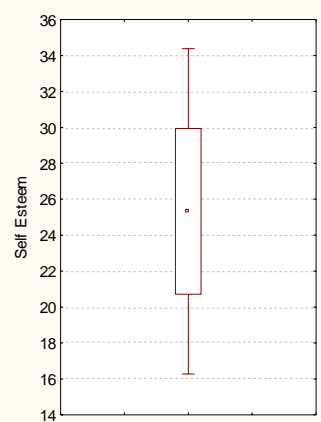

Figure 5. Selected summary statistics for the variable, Self Esteem, AAMU participants.

\section{Summary: Stress}
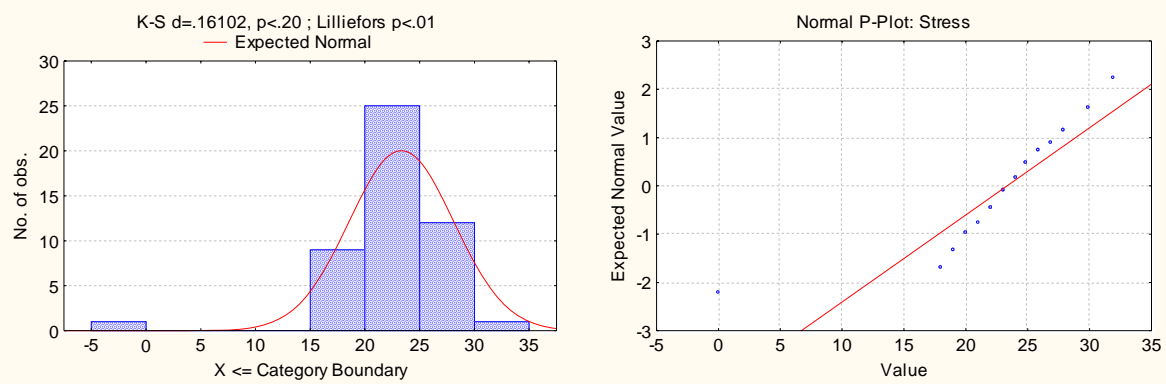

$$
\begin{aligned}
& \text { Summary Statistics:Stress } \\
& \text { Valid } \mathrm{N}=48 \\
& \text { Mean }=23.333333 \\
& \text { Median }=23.000000 \\
& \text { Minimum }=0.000000 \\
& \text { Maximum }=32.000000 \\
& \text { Std.Dev. }=4.781762
\end{aligned}
$$

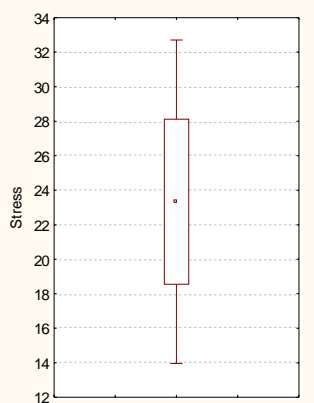

Figure 6. Selected summary statistics for the variable, Stress, $A A M U$ participants. 
Summary: Anxiety
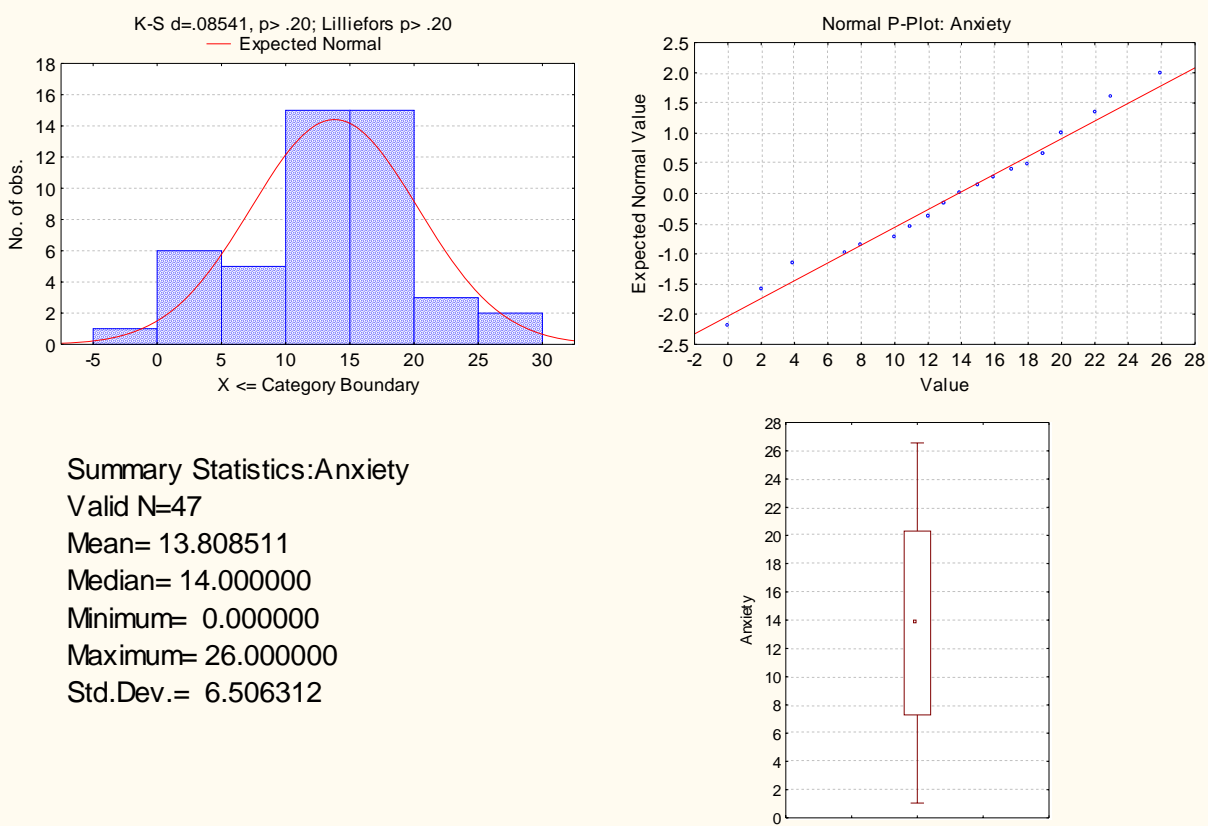

Figure 7. Selected summary statistics for the variable, Anxiety, AAMU participants.

Summary: Age
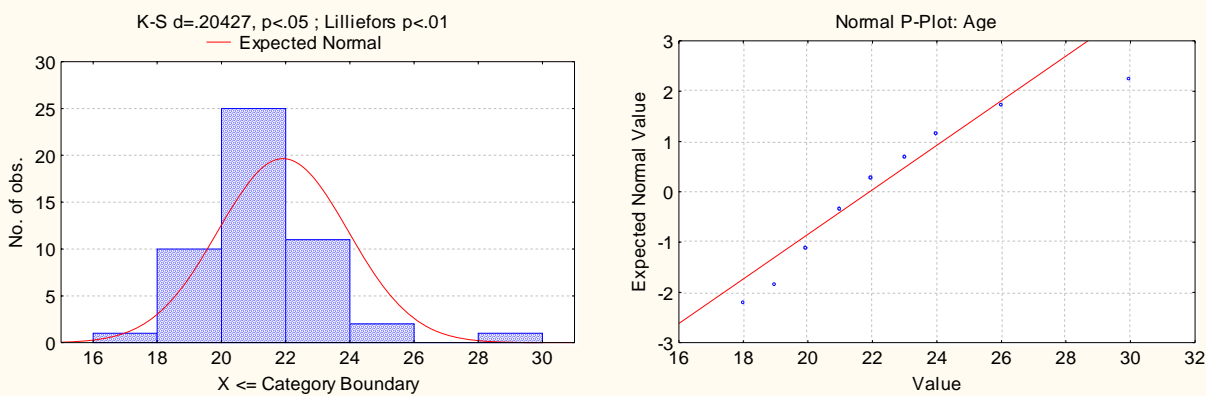

$$
\begin{aligned}
& \text { Summary Statistics:Age } \\
& \text { Valid } \mathrm{N}=50 \\
& \text { Mean }=21.920000 \\
& \text { Median }=22.000000 \\
& \text { Minimum }=18.000000 \\
& \text { Maximum }=30.000000 \\
& \text { Std.Dev. }=2.028773
\end{aligned}
$$

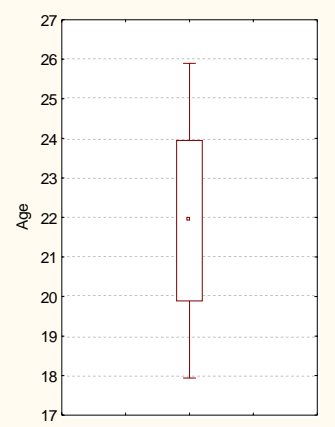

Figure 8. Selected summary statistics for the variable, Age, AAMU participants. 


\section{Data analysis for University of Alabama in Birmingham (UAB) participants}

\section{Self Esteem}

The authors analyzed the association between the alcohol consumptions and self esteem levels among UAB students. The scatter plot in Figure 9 shows that many respondents with high self esteem do not report drink alcohol (what is indicated as 2). By using the Spearman Rank Order Correlation, as shown in Table 5, we found a significant weak positive correlation between these variables of 0.182086 . This shows that higher self esteem is associated with less alcohol consumption.

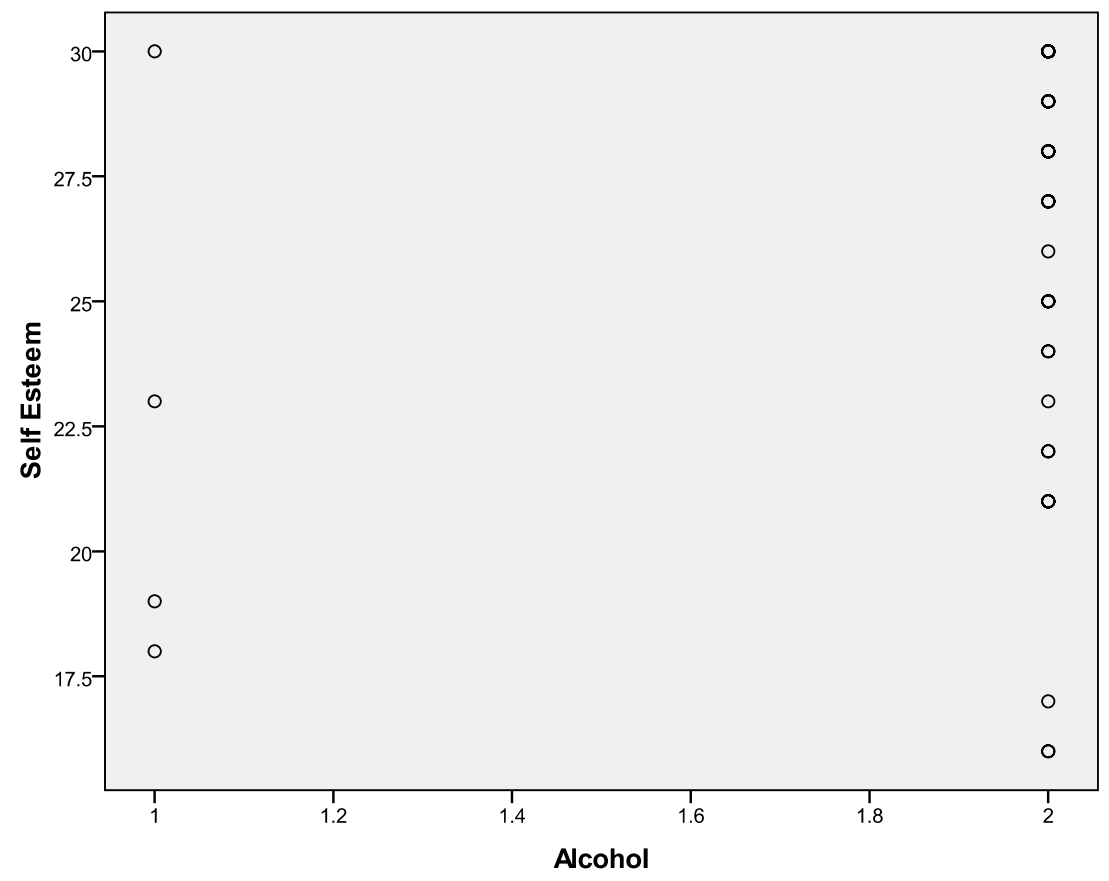

Figure 9. Scatter plot of alcohol consumption and self esteem among $U A B$ participants.

Table 5. Spearman Rank Order Correlation between Alcohol Consumption and Self Esteem among UAB Participants

\begin{tabular}{ccc}
\hline Variable & Alcohol Consumption & Self Esteem \\
\hline Alcohol Consumption & 1.0 & 0.182086 \\
Self Esteem & 0.182086 & 1.0 \\
\hline
\end{tabular}

Correlations are significant at $\mathrm{p}<05000$.

\subsection{Stress}


The association between the alcohol consumptions and stress levels was next considered. Based upon the scatter plot in Figure 10, respondents with higher stress level were more likely to consume alcohol (Indicated as 1) than the respondents with lower stress levels. The Spearman Rank Order Correlation analysis also indicated that significant negative correlation existed between alcohol use among them and the Spearman Rank order correlation is -0.214342. As in the case of AAMU students, this indicates that higher stress levels are associated with alcohol consumption.

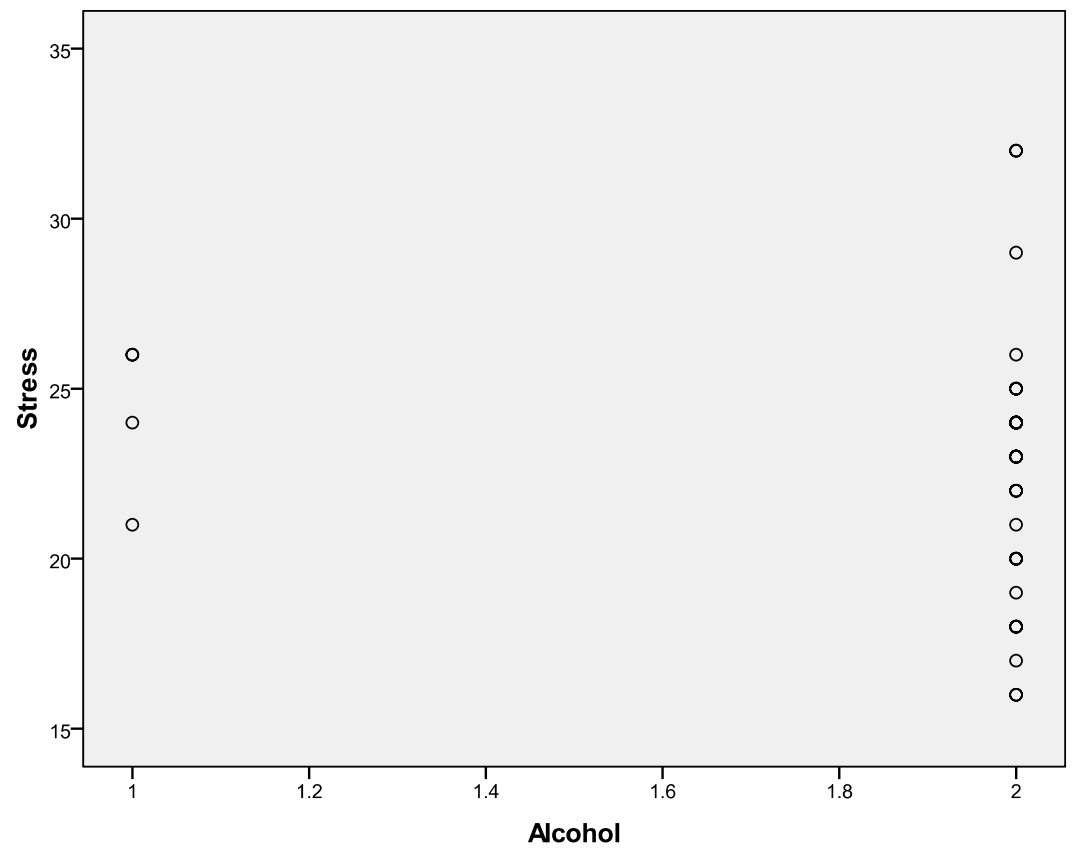

Figure 10. Scatter plot of alcohol consumption and stress among UAB participants.

Table 6. Spearman Rank Order Correlation between alcohol consumption and stress among UAB participants

\begin{tabular}{ccc}
\hline Variable & Alcohol Consumption & Stress \\
\hline Alcohol Consumption & 1.0 & -0.214342 \\
Stress & -0.214342 & 1.0 \\
\hline
\end{tabular}

Correlations are significant at $\mathrm{p}<05000$.

\subsection{Anxiety}

The scatter plot in Figure 11 depicts the association between the alcohol consumptions and anxiety levels. From Figure 11 it is evident that respondents with higher anxiety levels are more likely to consume alcohol than respondents with lower anxiety levels. The Spearman Rank Order Correlation analysis in Table 7 further supports this finding; anxiety levels and alcohol consumption have a significant weak negative correlation of - 
0.181192. From this finding we conclude that higher anxiety levels are associated with alcohol consumption.

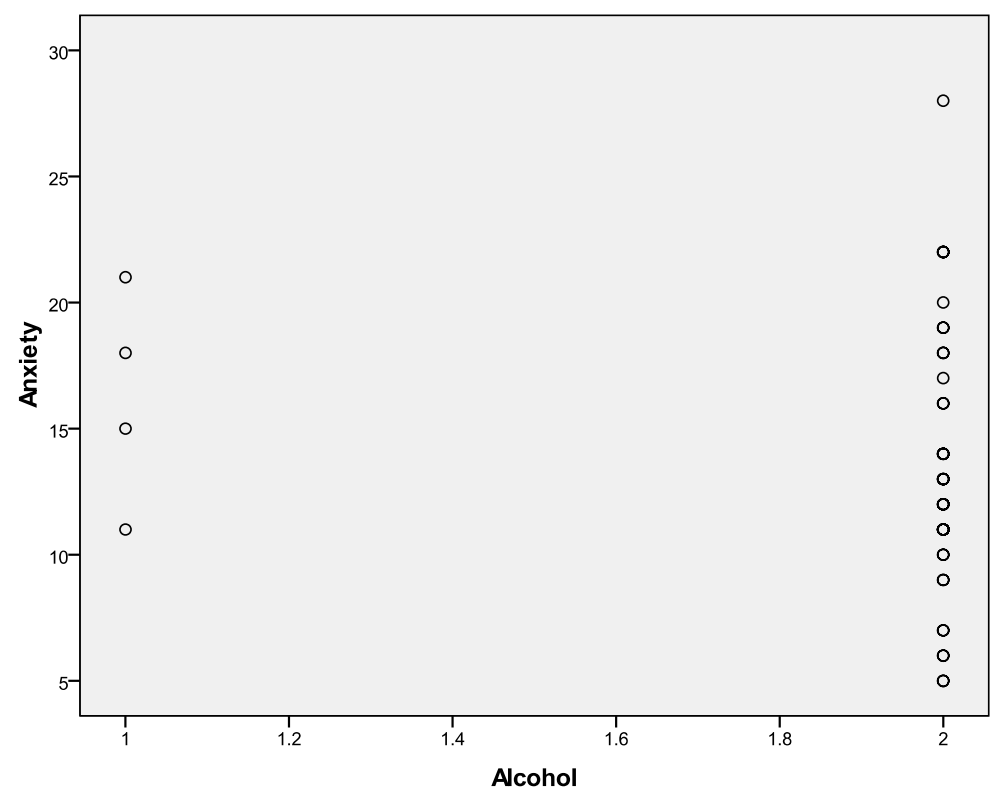

Figure 11. Scatter plot of alcohol consumption and anxiety among $U A B$ participants.

Table 7. Spearman Rank Order Correlation between alcohol consumption and anxiety among UAB participants

\begin{tabular}{ccc}
\hline Variable & Alcohol Consumption & Anxiety \\
\hline & & \\
Alcohol Consumption & 1.0 & -0.181192 \\
Anxiety & -0.181192 & 1.0 \\
\hline
\end{tabular}

\subsection{Age}

The authors analyzed the data to find the association between the alcohol consumptions and age. The scatter plot from Figure 12 shows that younger respondents are more likely to drink alcohol than older respondents. The Spearman Rank Order Correlation in Table 8 also indicates a weak positive correlation between age and alcohol consumption with a statistic of 0.302951 . This shows a greater likelihood of alcohol consumption among younger respondents. 


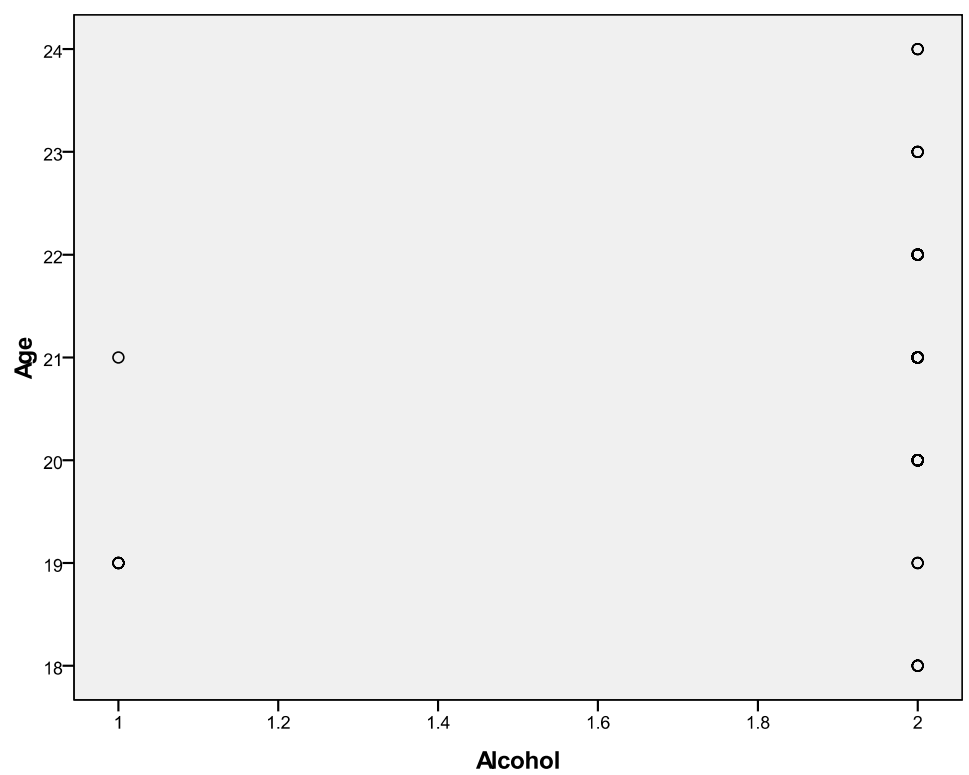

Figure 12. Scatter plot of alcohol consumption and age among $U A B$ participants

Table 8. Spearman Rank Order Correlation between alcohol consumption and age among UAB participants

\begin{tabular}{ccc}
\hline Variable & Alcohol Consumption & Age \\
\hline Alcohol Consumption & 1.0 & 0.302951 \\
Age & 0.302951 & 1.0 \\
\hline
\end{tabular}

Correlations are significant at $\mathrm{p}<05000$

UAB Respondents: Summary Statistical Analysis

In a similar manner as the AAMU survey, Figures 13, 14, 15 and 16 provide a summary statistical analysis of the distribution of respondent observations using descriptive statistics, a histogram and P-plot for self esteem, anxiety, stress and age. The UAB survey relied on a sample of 44 respondents. Findings concerning Average Age, Self Esteem, Stress and Anxiety levels were similar to the AAMU subjects. The Average Age of UAB respondents was 21 years within an interval of 18 to 24 years. The Average Self Esteem Level for UAB respondents is 25.61. The Average Stress Level for UAB respondents is 22.66. Average anxiety for UAB respondents is 13.59. As in the case of the AAMU respondents, each variable demonstrated distribution of responses consistent with the correlation analysis. 
Summary: Self Esteem
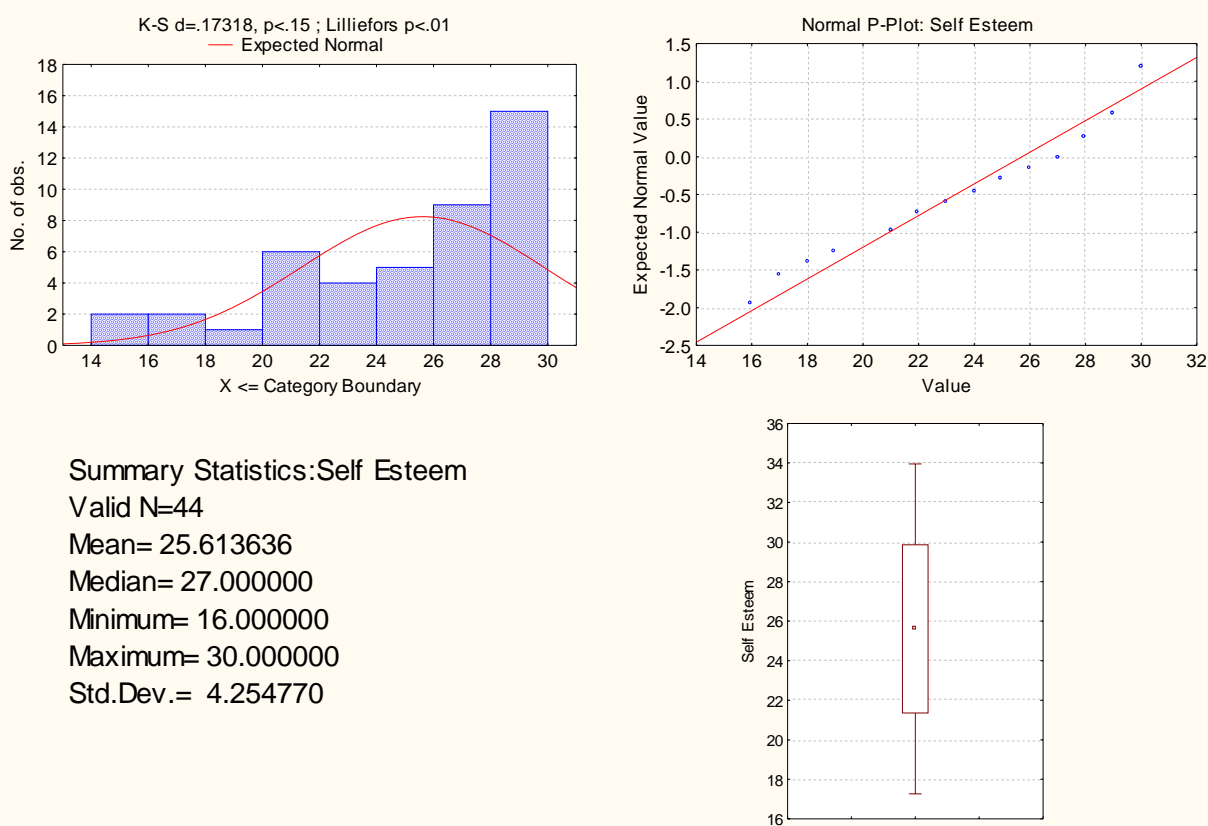

Figure 13. Selected summary statistics for the variable, Self Esteem, UAB participants.

Summary: Stress
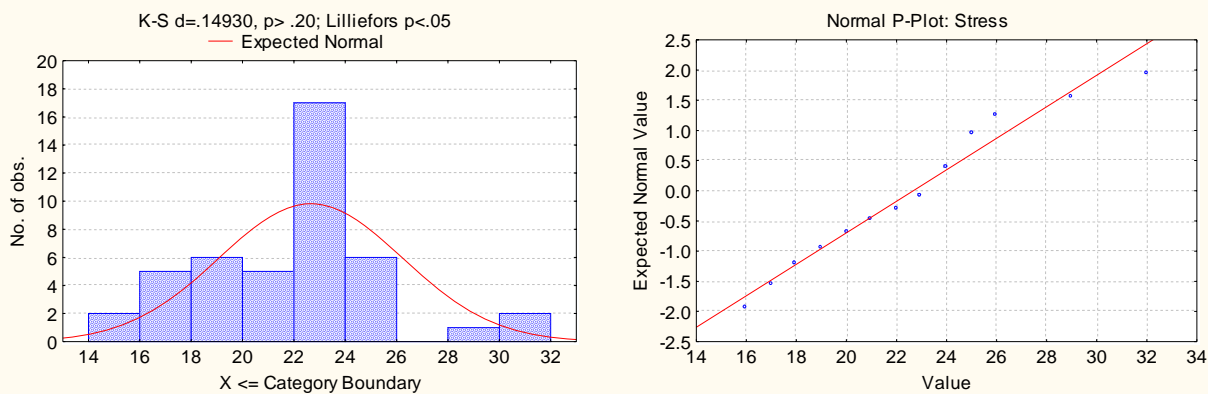

Summary Statistics:Stress

Valid $\mathrm{N}=44$

Mean $=22.659091$

Median $=23.000000$

Minimum $=16.000000$

Maximum $=32.000000$

Std.Dev. $=3.576039$

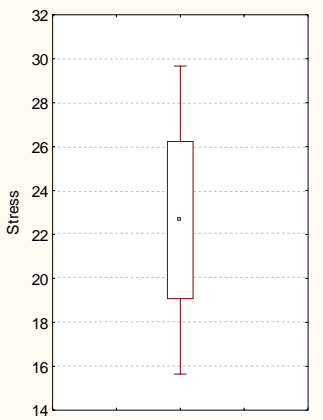

Figure 14. Selected summary statistics for the variable, Stress, $U A B$ participants. 
Summary: Anxiety
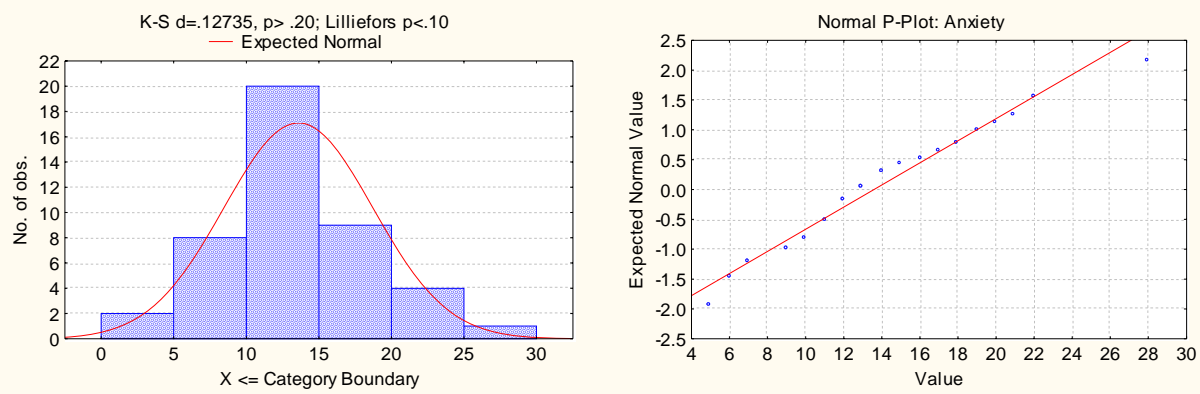

Summary Statistics:Anxiety

Valid $\mathrm{N}=44$

Mean $=13.590909$

Median $=13.000000$

Minimum $=5.000000$

Maximum $=28.000000$

Std.Dev.= 5.136817

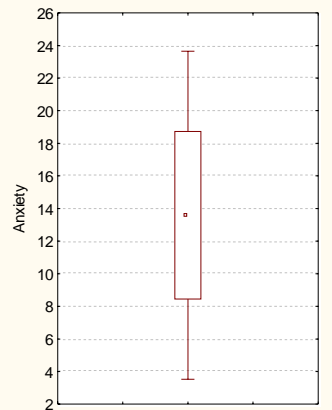

Figure 15. Selected summary statistics for the variable, Anxiety, $U A B$ participants.

Summary: Age
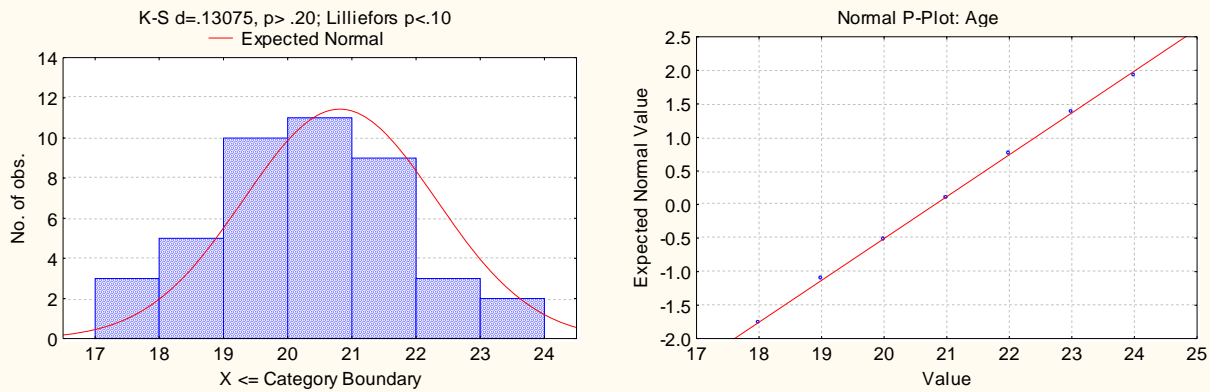

Summary Statistics:Age

Valid $\mathrm{N}=43$

Mean $=20.813953$

Median $=21.000000$

Minimum $=18.000000$

Maximum $=24.000000$

Std.Dev. $=1.500092$

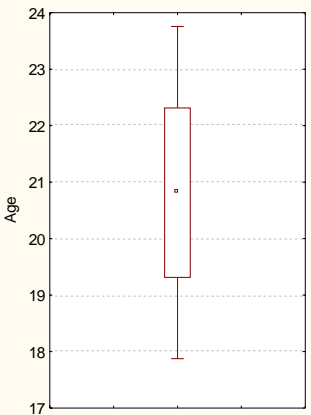

Figure 16. Selected summary statistics for the variable, Age, UAB participants. 


\section{Discussion}

In this study we explored how different psychological factors affect the college students' alcohol consumption behavior focusing on psychological factors of stress, self esteem and anxiety. The authors analyzed survey data to find the association between the alcohol consumption behavior and self esteem levels, alcohol consumption behavior and stress levels, alcohol consumption behavior and anxiety levels and alcohol consumption behavior and age. Scatter plots, Spearman Rank Order Correlation and descriptive statistical estimates were analyzed. The following findings were consistent between both universities:

Higher levels of self esteem were associated with low alcohol consumption. For both AAMU and UAB students, the association between alcohol consumption behavior and self esteem levels had significant weak positive correlation. That is, higher self esteem is associated with lower alcohol consumption. Conversely, students with low self esteem reported greater levels of alcohol consumption

Students which reported higher levels of stress also consumed more alcohol. The association between alcohol consumption behavior and stress levels for respondents had significant negative Spearman Rank Order Correlation estimates for both AAMU and UAB students. In both cases, higher stress levels were associated with alcohol consumption.

Students experiencing higher anxiety levels were more likely to consume alcohol. Alcohol consumption and anxiety levels for AAMU respondents had significant weak negative correlation. Similar findings were reported for UAB respondents. The same findings were evident for UAB Students in this sample.

Age was also a factor in levels of alcohol consumption. The association between alcohol consumption behavior and age for AAMU and UAB respondents had weak positive Spearman Rank Order Correlations. That is, younger students tended to report higher levels of alcohol consumption than their older cohorts.

From the analysis we can conclude that low self esteem, higher stress and anxiety levels and younger age increase the likelihood of consuming alcohol. These finding are important in developing effective strategies which address SUA, as they suggest psychological factors are behind consumptive behavior. This calls for forms of reactive intervention which includes counseling and proactive measures such as education.

Second, this study can be used to identify members of the student population that are most likely to suffer from SUA. It is evident in this research and other works that SUA generally afflicts the younger segment of student population.

These findings also have implications for addressing other forms of SUA such as tobacco, marijuana and drug use. Psychological factors examined in this study such as self esteem have also been associated with other types of SUA.

In closing, while we were both surprised and encouraged by the consistency in findings between students in two universities, we are also aware of a potential for regional bias; both universities are located in northern Alabama. We recommend that further cross sectional analyses be conducted in other parts of the United States. In this manner, issues concerning regional bias can be addressed while providing a further opportunity to test psychological factors associated with SUA. Measurement of these factors on the same 
participants before and after interventional programs would also be useful in assessing the effectiveness of these programs.

\section{References}

Atwoli, L., Mungla, P., Ndunga'u, M., Kinoti, K., \& Ogot , E. (2011). Prevalence of substance use among college students in Eldoret, western Kenya. BMC Psychiatry. 11 (34)

[Online]. Available: http://www.biomedcentral.com/1471-244X/11/34/.

Clasen, D. \& Brown, B. (1985). The multidimensionality of peer pressure in adolescence. Journal of Youth and Adolescence, 14 (6), 451-467

Cohen, S., Kamarck, T., \& Mermelstein, R. (1983) A global measure of perceived stress. Journal of Health and Social Behaviours, 24 (4), 385-396

Deas, D., \& Thomas, S. (2002). Comorbid Psychiatric Factors Contributing to Adolescent Alcohol and Other Drug Use. National Institute on Alcohol Abuse and Alcoholism. [Online]. Available: http://pubs.niaaa.nih.gov/publications/arh26-2/116-121.htm.

Dhanookdhary, A. Gomez, A. Khan, R., Lall, A., Murray, D., Prabhu, A., Ragoonath, A., Singh, N., Tewari, S., \& Youssef, F. (2010). Substance use among university students at the St Augustine Campus of The University of the West Indies. West Indian Medical Journal, 59 (6), 641-659.

Ham, L., \& Hope, D. (2003) College students and problematic drinking: A review of the literature. Clinical Psychology Review 23, 719-759

Hartup, W. (1999). Peer Experience and Its Developmental Significance. In Developmental Psychology: Achievements and Prospects, Bennett, M. (Ed.) Philadelphia, PA: Psychology Press.

Kilpatrick, D., Acierno, R., Saunders, B., Resnick, H., Best, C., \& Schnurr, P. (2000). Risk factors for adolescent substance abuse and dependence data from a national survey. Journal of Consulting and Clinical Psychology, 68 (1), 19-30.

Livneh, H., \& Redding, C. (1986). A factor analytic study of manifest anxiety: a trans-situational, trans-temporal investigation. The Journal of Psychology, 120, 253-263

Patterson, F., Lerman, C., Kaufmann, V., Neuner, G., \& Audrain-McGovern, J. (2004). Cigarette smoking practices among American college students: Review and future directions. Journal of American College Health, 52 (5), 203-210.

Peltzer, K., Malaka, D., Phaswana, N. (2002). Sociodemographic factors, religiosity, academic performance, and substance use among first-year university students in South Africa. Psychological Reports, 91, 105-113.

Rigotti, N., Lee, J., \& Wechler, H. (2000). U.S. college students' use of tobacco products: Results of national survey. Journal of the American Medical Association, 284, 699-705.

Rigotti, N., Morgan, S., \& Wechsler, H. (2005) US College Students' Exposure to Tobacco Promotions: Prevalence and Association With Tobacco Use. American Journal of Public Health, 95(1), 138-144.

Rosenberg, M. (1965). Society and the Adolescent Self-Image. Princeton, NJ: Princeton University Press.

Santor, D., Messervey, D., \& Kusumakar, V. (2000). Measuring peer pressure, popularity, and conformity in adolescent boys and girls: Predicting school performance, sexual attitudes, and substance abuse. Journal of Youth and Adolescence. 29 (2), 163-182.

Taylor, J. (1953). A personality scale of manifest anxiety. Journal of Abnormal and Social Psychology, 48(2), 285-290.

Windle, M. (2003). Alcohol use among adolescents and young adults. Alcohol Research and Health, 27 (1), 79-85 